\title{
Tripanossomíase bovina na região de Ibiraci/MG - relato de caso
}

Luisa Pucci Bueno Borges ${ }^{[a]}$, Ana Paula Amaral Almeida $a^{[b]}$, Pedro Paulo Maia Teixeira ${ }^{[a]}$, Renata Sitta Gomes Mariano ${ }^{[c]}$, Felipe Farias Pereira da Câmara Barros ${ }^{[b]}$, Lucas de Freitas Pereira[ ${ }^{[b]}$

\author{
[a] Universidade Federal do Pará (UFPA), Castanhal, PA, Brasil \\ [b] Universidade de Franca (UNIFRAN), Franca, SP, Brasil \\ [c] Universidade Estadual Paulista (UNESP), Jaboticabal, SP, Brasil
}

*Autor correspondente

e-mail: luisa_pucci@hotmail.com

\section{Resumo}

Atualmente com distribuição em todos os continentes, o Trypanossoma spp. é um hemoparasita de alta relevância na pecuária bovina, com potencial de levar altos prejuízos aos produtores. 0 Trypanossoma vivax é a espécie que mais acomete rebanhos nacionais, levando a grandes impactos sanitários. Em uma propriedade de produção leiteira, localizada no município de Ibiraci/MG, foram observados em cinco animais de um rebanho de 90 fêmeas em lactação, queda de produção, emagrecimento progressivo, lacrimejamento e repetição de cio. Aproximadamente dois meses após as manifestações iniciais, foram verificados mais dez animais com sintomatologia semelhante às anteriormente descritas. Um dos bovinos que apresentavam sintomatologia foi encaminhado ao Hospital Veterinário da Universidade de Franca (UNIFRAN), sendo este o mais debilitado. Além dos sinais clínicos já citados, também apresentava incoordenação motora, dificuldade de se levantar e deitar. No exame físico foi possível verificar desidratação, temperatura de 39,5ํㅡ e frequência cardíaca de 90 batimentos por minuto. Foram realizadas avaliações hematológica e bioquímica, verificando leucocitose, linfocitose e AST aumentada. Realizou-se esfregaço sanguíneo de ponta de orelha, podendo-se observar elevada quantidade de parasitas na forma tripomastigota, característico de T. vivax. Após o diagnóstico prévio de tripassomíase, o animal foi medicado com cloridrato de oxitetraciclina e diaceturato de diminazene. A partir desse achado, coletou-se sangue dos 15 animais que apresentavam sintomatologia semelhante e os espécimes foram encaminhados para diagnóstico complementar pela técnica de imunofluorescência indireta, no qual o resultado obtido foi positivo para tal enfermidade nas amostras sanguíneas de todos os animais. Os 15 animais foram medicados com cloridrato de oxitetraciclina e diaceturato de diminazene, sendo observada melhora sintomática em relação ao estado clínico de todos 
os animais tratados. 0 paciente internado no Hospital Veterinário veio a óbito, e na necropsia encontrouse macroscopicamente presença de abscessos hepáticos, sufusão pericárdica e baço friável. As doenças parasitárias têm causado grande tormento tanto para o homem quanto para os animais, tendo maior controle apenas em países mais desenvolvidos. Dentre essas enfermidades, a tripanossomíase se encontra na lista das mais importantes. Além do tratamento, é importante que seja feito profilaxia desta doença, principalmente em áreas endêmicas, como o controle das moscas hematófogas, realização de exames sorológicos periódicos e controle dos animais infectados das áreas livres da enfermidade, tais ações implicam no uso correto das drogas tripanocidas. 